\title{
Inhaltsverzeichnis zu Band II
}

3. Lineare Automaten

3.1. Die allgemeine Response-Formel und das Superpositionsprinzip. . . . . . . . . . . . . . . . . . . . 5

3.2. Lineare sequentielle Schaltkreise . . . . . . . . . 8

3.3. Minimierung . . . . . . . . . . . . . . . . . . . 11

3.4. Lineare Darstellungen . . . . . . . . . . . . . . . 17

3.5. Übertragungsfunktion . . . . . . . . . . . . . . . . . . 21

3.6. 0-initial-Äquivalenz und minimale Modellbildung . . . 32

3.7. Erzeugung von Gruppenkodes durch lineare Automaten 44

3.8. Beschreibung eines Selektionsprozesses. . . . . . . 50

4. Schieberegister

4.1. Definitionen und grundlegende Eigenschaften. . . . . 57

4.2. Periodische Erzeugung vorgegebener Binärfolgen . . . 61

4.3. Pseudo-Zufallszahlen . . . . . . . . . . . . . . . 75

4.4. Lineare Schieberegister . . . . . . . . . . . . . . 80

4.5. Zyklische Kodes . . . . . . . . . . . . . . . . . . 88

4.6. Frequenzteiler . . . . . . . . . . . . . . . 95

Anhang II

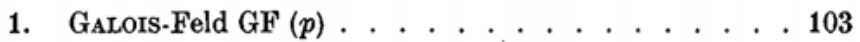

2. Z-Transformation . . . . . . . . . . . . . . 104

3. Matrizen . . . . . . . . . . . . . . 107

4. Auflösung linearer binärer Gleichungssysteme. . . . . 111

Literatur. . . . . . . . . . . . . . 113

Sachverzeichnis . . . . . . . . . . . 116 